\title{
The preparation and evaluation of self- nanoemulsifying systems containing Swietenia oil and an examination of its anti-inflammatory effects
}

\author{
This article was published in the following Dove Press journal: \\ International Journal of Nanomedicine \\ 7 October 2014 \\ Number of times this article has been viewed
}

\begin{abstract}
Ahmad M Eid'
Hesham A El-Enshasy'

Ramlan Aziz'

Nagib A Elmarzugi ${ }^{1,2}$

'Research and Innovation Department, Institute of Bioproduct Development, Universiti Teknologi Malaysia, Johor, Malaysia; ${ }^{2}$ Department of Industrial Pharmacy, Faculty of Pharmacy, Tripoli University and Biotechnology Research Center, Libyan Authority for Research, Science and Technology (LARST), Tripoli, Libya
\end{abstract}

\begin{abstract}
There is an increasing trend among pharmaceutical industries to use natural bioactive materials as medicinal agents and to use new technologies such as self-nanoemulsifying systems. The solubility and bioavailability of poorly soluble drugs can be enhanced by self-nanoemulsifying systems. Swietenia oil is frequently used because of its antimicrobial, antimutagenic, and anticancer bioactive medical properties. This study was conducted to develop self-nanoemulsifying systems for Swietenia oil that will enhance the anti-inflammatory activity of the oil. The self-emulsifying systems developed for Swietenia oil in this study were constructed using ternary phase diagrams and contained the nonionic surfactants Labrasol ${ }^{\circledR}$, Tween 20, Capmul ${ }^{\mathbb{R}}$, and Labrafil ${ }^{\circledR}$. The effect of these surfactants on the formulation was examined. The mean droplet size of Swietenia oil as well as their distribution, appearance, viscosity, and spreading times were studied to find the optimum formula, which contained droplets that were less than $200 \mathrm{~nm}$. The next step was to test the anti-inflammatory properties of the optimum formula using a carrageenan-induced rat paw edema test. The results from this test were compared to the oil solution. Different oil/surfactants mixtures had various emulsification properties that were related to the size of their droplets. Tween 20 is a good surfactant to use in self-emulsifying systems because it produces droplets of nano-size. Mixtures of Capmul/Labrasol at a ratio of 2:1 and Labrafil/Tween 20 at a ratio of 1:2 were able to produce self-nanoemulsifying formulations containing Swietenia oil concentrations that ranged from $20 \%-50 \%$. Nanoemulsion occurred when the size of the droplets fell below $200 \mathrm{~nm}$ with low size distribution $(<0.3)$ after being gently mixed with water. It was found that the hydrophilic/lipophilic balance value affected the ternary phase diagram behavior of Swietenia oil and surfactants. In addition, the anti-inflammatory properties of Swietenia oil were greater in the self-nanoemulsifying systems than in the oil solution.
\end{abstract}

Keywords: Labrasol, Capmul, Tween 20, Labrafil

\section{Introduction}

Nanoemulsions are isotropic dispersed systems with droplets that are between 20 and $200 \mathrm{~nm}$ in size. ${ }^{1-3}$ Due to the size of their droplets, nanoemulsions are kinetically stable and resist sedimentation and creaming. They also possess a high level of kinetic stability and optical transparency. ${ }^{4-6}$ Developing a nanoemulsion formula that involves a self-emulsifying system normally involves the combination of isotropic mixtures with an oil component and a surfactant in a specific ratio. When the correct ratio is used, the resulting compound will have the ability to form a nanoemulsion when dispersed with aqueous media and gently agitated..$^{7-9}$
Correspondence: Nagib A Elmarzug Institute of Bioproduct Development, Universiti Teknologi Malaysia, 81310 UTM Johor Bahru, Johor, Malaysia

Tel +60 75536473

Fax +60 75536464

Email nagib@ibd.utm.my 
Self-emulsifying systems offer a strategy for dealing with the low oral bioavailability of drugs that are not easily dissolved in water. ${ }^{10,11}$ The size of the droplets in an emulsion is critical to the behavior of the self-emulsifying systems because droplet size determines the rate at and level to which a drug is released and absorbed. ${ }^{12-17}$ Pharmaceutical formulas depend on the identification of a system that will spontaneously emulsify. The mechanism behind spontaneous emulsification with gentle agitation in an aqueous media such as gastrointestinal fluids is initiated when the change in entropy that favors dispersion is bigger than the force required to increase the surface area of the dispersed phase. ${ }^{3,18,19}$ Emulsification occurs spontaneously as a result of low and negative or positive free energy.

Self-emulsifying formula production involves combining oils and surfactants. The components used must be able to be taken orally, such as nonionic surfactants and oils with medium-chain triglyceride. Self-emulsifying systems impacted the concentration of surfactants and their hydrophilic/lipophilic balance (HLB). ${ }^{20,21}$

Swietenia oil is extracted from the plant seeds of Swietenia macrophylla, which is a member of the family Meliaceae. ${ }^{22}$ It is grown widely in the Pacific region and in more than 40 countries in Southern Asia. ${ }^{22-24}$ S. macrophylla seeds are collected from its fruit ("sky fruit"). ${ }^{24}$ The S. macrophylla tree has a variety of medicinal properties and it is used in the treatment of hypertension, cancer, diabetes, malaria, chest pains, intestinal parasites, and amebiasis..$^{25,26}$ It also has antifungal, antibacterial, ${ }^{27,28}$ antinociceptive, ${ }^{29}$ antimicrobial, ${ }^{30}$ and antidiarrheal properties. ${ }^{31}$

\section{Materials and methods Materials}

The Swietenia oil used in this study was obtained from Nawa Pharma Sdn Bhd (Malaysia). Tween 20 (polyoxyethylene sorbitan monolaurate) was a product of Sigma-Aldrich Co. (St Louis, MO, USA). Labrafil ${ }^{\circledR}$ M1944CS (oleoyl macrogol-6 glycerides) and Labrasol ${ }^{\circledR}$ (caprylocaproyl macrogol-8 glycerides) were purchased from Gattefosse SAS (France) and Capmul ${ }^{\circledR}$ MCM C8 (glyceryl monocaprylate) was purchased from Abitec Corporation (USA).

\section{Methods}

\section{Preparation of self-nanoemulsifying systems}

Self-emulsifying systems were formulated by combining Swietenia oil with different surfactants and cosurfactants as described by Eid et al. ${ }^{32}$ Five different surfactant mixtures containing Swietenia oil were kept at a constant temperature and these formed the basis of ternary phase diagrams. System 1 was composed of a mixture of oil, Capmul/Labrasol (2:1), and Labrafil/Tween 20 (1:2). System 2 consisted of Swietenia oil, Capmul, and Tween 20. System 3 was a mixture of Swietenia oil, Labrafil, and Tween 20, whereas System 4 combined Swietenia oil, Capmul, and Labrasol. Finally, System 5 comprised a mixture of Swietenia oil, Labrafil, and Labrasol. These combinations were used to examine how emulsification was affected by different parameters.

Each formulation was prepared by weighing the Swietenia oil and surfactants with an analytical balance (Mettler Toledo) and based on a ternary phase diagram. The oil and surfactants were homogenized for 2 minutes by vortex mixer. Then, a sample was dispersed in distilled water under gentle agitation. The resulting emulsion droplet size was measured to find the efficient emulsification formula. All experiments were carried out in triplicate at a constant temperature $\left(25^{\circ} \mathrm{C}\right)$.

Nanoemulsion areas were marked on the ternary phase diagrams to indicate transparency and the presence of fine droplets $(>1,000 \mathrm{~nm})$. Areas of macroemulsion were also marked to indicate whiter, isotropic solutions that could contain micelle solutions $(1-20 \mu \mathrm{m})$. Regions that were visibly cloudy indicated areas of coarse emulsion $(20-100 \mu \mathrm{m})$.

\section{The size of the droplets, their distribution,} and a zeta potential analysis

To observe the size and distribution of the droplets, a $250 \mu \mathrm{L}$ sample of Swietenia oil and surfactant mixture was self-emulsified in $300 \mathrm{~mL}$ of distilled water. The mixture was gently agitated with a glass rod. The size and size distribution of the droplets were examined using a Mastersizer 2,000 particle size analyzer (Malvern Instruments, Malvern, UK) for the resulting emulsion. Size and distribution measurements were taken in triplicate. This step was part of the screening study of the ternary phase diagram. A Malvern Zetasizer Nano was used to perform a zeta potential analysis on formulations with droplets that were smaller than $200 \mathrm{~nm}^{32}$

\section{Visual observation}

The emulsification process and the tendency of the formulas to emulsify spontaneously were observed by selfemulsification when dispersing at a $250 \mu \mathrm{L}$ sample of an oil/ surfactants mixture in $300 \mathrm{~mL}$ of distilled water. A glass rod was used to gently agitate the mixture. A good emulsion was reflected by droplets that self-emulsified easily in distilled 
water and produced a fine milky emulsion. A moderate emulsion required longer to emulsify and produced a milky emulsion. A poor emulsion or no emulsion is considered to be formed when the oil droplets immediately coalesce. In this study, the ability of the emulsion to spread, mix, and easily disperse in distilled water was observed. The time to emulsification represented the length of time required for the formula to emulsify.

\section{Self-nanoemulsifying formulations' viscosity}

A Brookfield viscometer (Wingather 2.1 software) was used to measure the viscosity of self-nanoemulsifying formulations at $25^{\circ} \mathrm{C} \pm 1^{\circ} \mathrm{C}$. A $31 \mathrm{~s}$-sized spindle was used. The spindle speed began at $40 \mathrm{rpm}$ and increased in $10 \mathrm{rpm}$ increments every minute until $120 \mathrm{rpm}$ was reached. The viscosity, in centipoises (cP), was calculated by multiplying the density of the sample with the resulting value. ${ }^{32}$

\section{In vivo anti-inflammatory study}

The technique proposed by Winter et $\mathrm{al}^{33}$ was used to evaluate the anti-inflammatory properties of each mixture. Forty-eight hours before the beginning of the experiment, 60 male Sprague Dawley rats were randomly selected. Each rat weighed between 180 and $200 \mathrm{~g}$. The guidelines developed by Universiti Teknologi MARA for the care of laboratory animals and the ethical standards for investigating pain conscious animals were followed for the duration of this study. The rats were kept at room temperature $\left(25^{\circ} \mathrm{C} \pm 2^{\circ} \mathrm{C}\right)$ with $60 \%-70 \%$ humidity and a 12-hour light/darkness cycle in the animal holding unit. A sample of $0.1 \mathrm{~mL}$ of a $1 \%$ suspension of carrageenan and saline was injected in the subplantar region of the right hind paw of each rat to cause edema.

The rats were divided into ten groups of six rats. The first four groups were injected with different concentrations of Swietenia oil solution $(0.5,1,2$, and $4 \mathrm{~mL} / \mathrm{kg})$. The fifth, sixth, seventh, and eighth groups received a self-nanoemulsifying formulation containing Swietenia oil in different concentrations $(0.5,1,2$, and $4 \mathrm{~mL} / \mathrm{kg})$. The ninth group acted as a positive control group. Each member of the ninth group received $200 \mathrm{mg} / \mathrm{kg}$ of acetylsalicylic acid. The tenth group was injected with saline and they served as a negative control in this experiment.

Sixty minutes after injection of either a Swietenia oil solution, a self-nanoemulsifying formulation, or acetylsalicylic acid, all the rats received an injection of carrageenan. Paw volumes were measured every hour for the next 4 hours using a digital paw edema meter (520-R; IITC Life Science, USA). ${ }^{34,35}$ The amount of swelling caused by the carrageenan injections at the specified intervals was calculated as a percentage of difference in the mean paw thickness before and after the carrageenan injection divided by the initial thickness of the paw, as shown below:

$$
\begin{aligned}
\% \text { change of hind paw volume }= & ([\text { mean } \mathrm{Cn}-\text { mean } \mathrm{Ci}] / \\
& \text { mean } \mathrm{Ci}) \times 100
\end{aligned}
$$

where $\mathrm{Ci}$ is the initial volume of the hind paw and $\mathrm{Cn}$ is the hind paw volume at specific intervals following the carrageenan injection. ${ }^{36-38}$

\section{Statistical analysis}

A one-way analysis of variance (ANOVA) was used to statistically analyze the anti-inflammatory effects. $P<0.05$ indicated a statistically significant difference.

\section{Results and discussion}

After several different mixtures of Swietenia oil and surfactants were prepared, they were examined for their selfemulsification abilities when they were subjected to gentle agitation in water. Figures $1-5$ show the ternary phase diagrams of Swietenia oil with different surfactant/cosurfactant mixtures. The different areas in each ternary diagram represent isotropic emulsion, transparent emulsion, separation emulsion, and coarse emulsion.

System 1 (Figure 1) consisted of Swietenia oil and four different surfactant/cosurfactant mixtures. Those mixtures produced the largest nanoemulsion region compared to the other ternary phase diagrams. This large region of nanoemulsion was explained by the presence of different surfactant

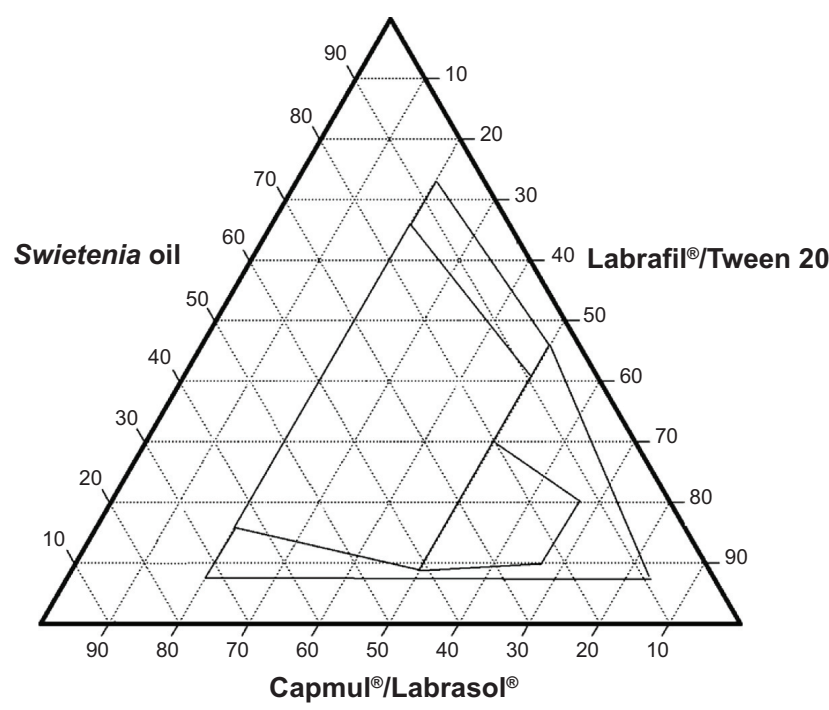

Figure I Ternary phase diagram of System I. 


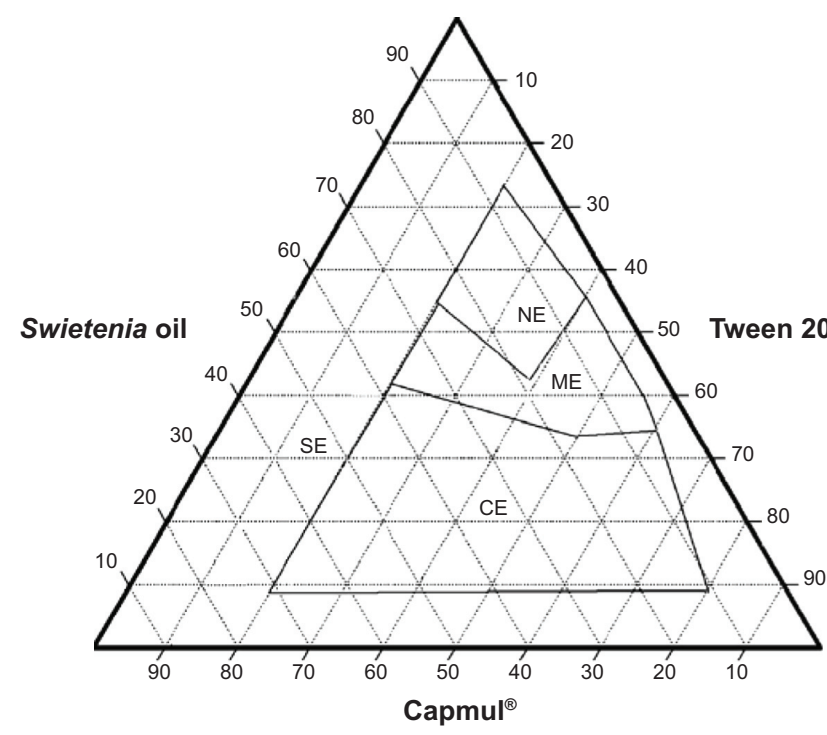

Figure 2 Ternary phase diagram of System 2.

Abbreviations: CE, coarse emulsion; ME, macroemulsion; NE, nanoemulsion; SE, separation emulsion.

mixtures that facilitated the preparation of many series of formulations and led to the development of nanoemulsion formulas with enhanced stability. Moreover, Figures 2 and 3 (ternary phase diagrams) show moderate levels of emulsification. The areas of nanoemulsion were smaller in the corresponding formulations, and these formulations did not remain stable overnight. Ternary phase diagrams are shown in Figures 4 and 5. The two corresponding formulations had poor nanoemulsion as they produced only macroemulsions.

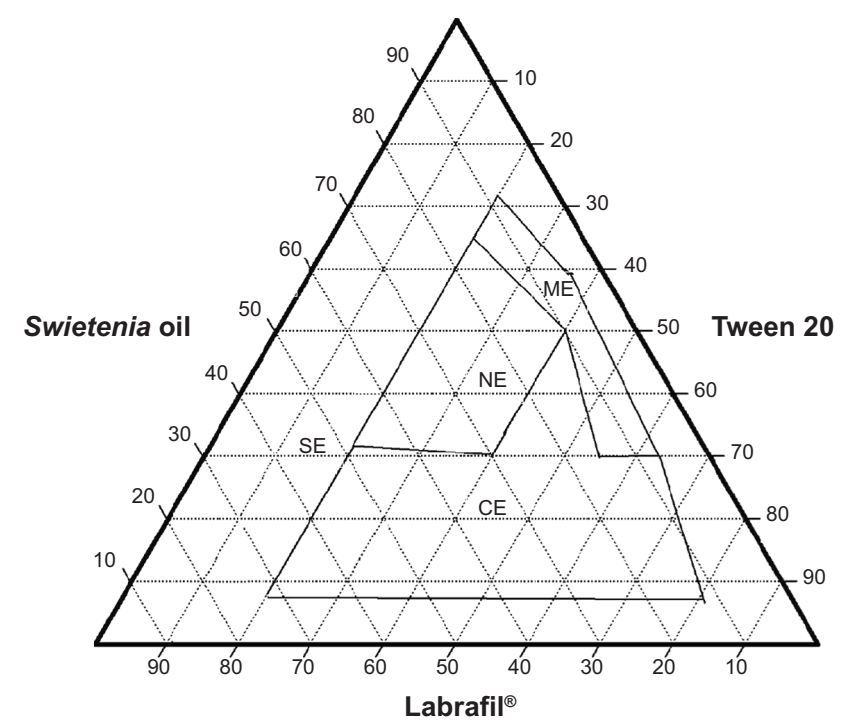

Figure 3 Ternary phase diagram of System 3.

Abbreviations: CE, coarse emulsion; ME, macroemulsion; NE, nanoemulsion; SE, separation emulsion.

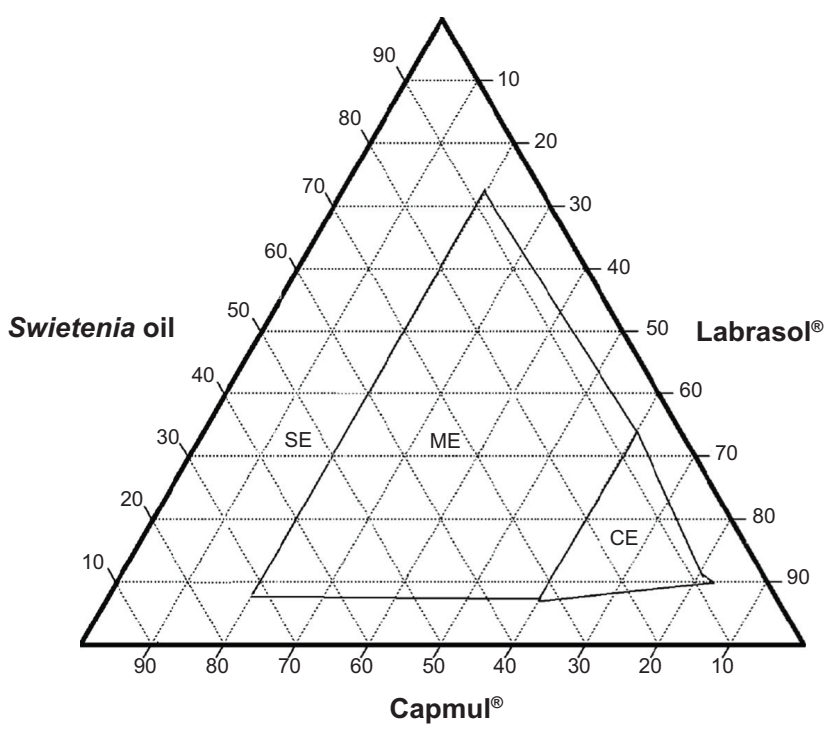

Figure 4 Ternary phase diagram of System 4.

Abbreviations: $\mathrm{CE}$, coarse emulsion; $\mathrm{ME}$, macroemulsion; $\mathrm{SE}$, separation emulsion.

The ternary phase diagram for System 1 shows nanoemulsions produced with oil concentrations between $20 \%$ and $50 \%$ and mixed with different concentrations of Capmul/Labrasol at a ratio of 2:1 and Labrafil/Tween 20 at a ratio of $1: 2$. This suggests a maximum oil concentration and a minimum surfactants concentration. Mixing different surfactants yielded better self-nanoemulsifying systems with nano-size droplets below $200 \mathrm{~nm}$.

Combining different types of surfactants/cosurfactants contributed to more accurate results compared to the results

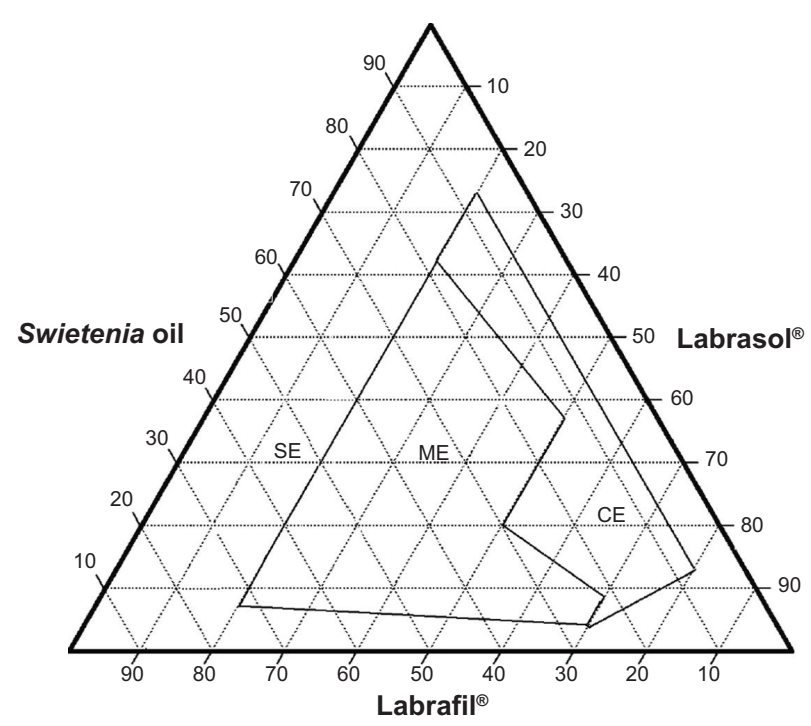

Figure 5 Ternary phase diagram of System 5.

Abbreviations: $\mathrm{CE}$, coarse emulsion; $\mathrm{ME}$, macroemulsion; $\mathrm{SE}$, separation emulsion. 
of using only a single surfactant. The nanoemulsion region in the ternary phase diagram of System 1 was greatly increased and the oil concentrations were broader as different amounts of oil was used in each formulation. Pouton ${ }^{39}$ reported that, when developing a self-emulsifying formula, choosing the surfactants with the right combination of high and low HLBs is critical to the successful formulation of a microemulsion. Surfactants with high HLB values have excellent spreading and rapid self-emulsification properties. On the other hand, low HLB surfactants display poor spreading characteristics, poor self-emulsifying properties, and long emulsification times.

The surfactant selection is important in achieving the optimum self-nanoemulsifying formulation. Each oil and surfactant has a specific HLB. The right selection of surfactant or surfactant mixture HLB value that matches the selected oil HLB value will help in achieving the water and oil phases with the lowest interface tension. Self-emulsifying systems are extremely sensitive to the ratio of oils to surfactants/cosurfactants in the mixture. In the ternary phase diagram of System 1, Tween 20 shows a high HLB value. It was chosen as a nonionic surfactant because it produced superior self-emulsifying systems with faster emulsification times and fine oil-in-water droplets. Combining Labrafil (HLB 4) and Tween 20 (HLB 16.7) at a 1:2 ratio enhanced the self-emulsification properties. Used alone, Tween 20 has high hydrophilic groups that produce an immiscible oil/ surfactant mixture and will cause poor self-emulsification properties in the resulting product if very hydrophobic oils are used. In this study, Labrafil was added to improve the self-emulsification properties of the system and make it more stable.

Combining Capmul (HLB 5-6) and Labrasol (HLB 14) at a ratio of 2:1 also facilitated the solubility of hydrophobic oil components to create a stable self-emulsifying system. A combination of Capmul and Labrasol was used in System 4, while in System 5, a mixture of Labrafil and Labrasol. These two combinations resulted in a ternary phase diagram with a large region of macroemulsion and no nanoemulsion region, indicating that these combinations did not produce nanoemulsion, but would be suitable for self-macroemulsion formulations. These results are supported by Gao and Morozowich, ${ }^{40}$ who maintained that high HLB values of nonionic surfactants in selfemulsifying drug delivery systems demonstrated the immediate formation of oil-in-water droplets and that the formula rapidly spread in aqueous media. These systems were also very stable.
System 2 combined Capmul and Tween 20 and System 3 combined Labrafil and Tween 20. Both systems exhibited the ability to produce nanoemulsions. This indicates that Tween 20 was a good nonionic surfactant and that it is suitable for producing a self-nanoemulsion system because it possesses good solubility properties. When Tween 20 was not added to a system, poor nanoemulsions were produced, as shown in Systems 2 and 3. Additionally, when surfactants with high HLB values (Labrasol) were used to prepare self-emulsifying systems, the performance of those systems was worse if Tween 20 was not added. Only the right mixture of surfactants will produce a suitable selfnanoemulsion system. Mahdi et $\mathrm{al}^{41}$ experienced similar results with blends containing nonionic surfactants Tween and Tween $/$ Span $^{\circledR}$, which had been screened with water for their solubilization capability for palm kernel oil esters. Mahdi et al's ${ }^{41}$ results confirmed that the solubilizing capacity of Tween 20 is higher compared to other surfactants; in addition, high HLB blends of surfactants and cosurfactants have better solubility properties compared to blends with lower HLB values.

\section{Swietenia oil and surfactant blends' behavior on droplet size, size distribution, and zeta potential}

To categorize where emulsion formation occurred, Swietenia oil and surfactants/cosurfactants mixtures were studied for their droplet size and size distribution. It was revealed in the ternary phase diagrams that the droplet sizes were different when different combinations of surfactants/cosurfactants were used. In a comparison of the ternary phase diagrams, System 1 had the finest droplet size and size distribution. The smallest droplet size produced by Swietenia oil was $111 \pm 1.4 \mathrm{~nm}$, with size distribution $0.177 \pm 0.007$. By comparison, System 2 had droplets that were $231 \pm 2.6 \mathrm{~nm}$ in size with size distribution $1.02 \pm 0.006$, and the droplets in System 3 were $189 \pm 1.7 \mathrm{~nm}$ in size with size distribution $0.469 \pm 0.009$. Systems 4 and 5 had the largest droplets. In System 4, droplet size was $1.07 \pm 2.8 \mu \mathrm{m}$ with size distribution 1.632 \pm 0.004 and, in System 5, the droplets were $1.103 \pm 2.3 \mu \mathrm{m}$ in size with size distribution $0.547 \pm 0.008$.

Table 1 sets out the compositions of the self-nanoemulsifying formulations from System 1, the size of their droplets, and their size distribution. Droplet size and size distribution were measured using a Malvern Mastersizer instrument. The Malvern Mastersizer instrument allows for measurements from $\mathrm{nm}$ to $\mu \mathrm{m}$. Formulations with droplet 
Table I Self-nanoemulsifying formulations of Swietenia oil in System I

\begin{tabular}{|c|c|c|c|c|c|c|}
\hline Formulation & 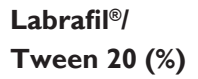 & $\begin{array}{l}\text { Capmul }^{\circledR} / \\
\text { Labrasol }^{\circledR} \text { (\%) }\end{array}$ & $\begin{array}{l}\text { Swietenia } \\
\text { oil (\%) }\end{array}$ & $\begin{array}{l}\text { Droplet size } \\
(\mathrm{nm}) \pm \text { SD }\end{array}$ & $\begin{array}{l}\text { Size } \\
\text { distribution } \pm \text { SD }\end{array}$ & $\begin{array}{l}\text { Zeta potential } \\
(\mathrm{mV})\end{array}$ \\
\hline A & 32.0 & 48.0 & 20.0 & $118 \pm 1.7$ & $0.283 \pm 0.007$ & -26.3 \\
\hline B & 40.0 & 40.0 & 20.0 & $119 \pm 1.6$ & $0.267 \pm 0.004$ & -28.6 \\
\hline C & 32.0 & 32.0 & 36.0 & $133 \pm 1.9$ & $0.37 I \pm 0.009$ & -26.4 \\
\hline D & 40.0 & 10.0 & 50.0 & $184 \pm 1.1$ & $0.293 \pm 0.006$ & -23.3 \\
\hline E & 48.0 & 32.0 & 20.0 & $I I I \pm I .4$ & $0.260 \pm 0.008$ & -28.9 \\
\hline $\mathrm{F}$ & 38.4 & 25.6 & 36.0 & $146 \pm 1.2$ & $0.255 \pm 0.005$ & -28.2 \\
\hline G & 56.0 & 24.0 & 20.0 & $126 \pm 1.7$ & $0.339 \pm 0.009$ & -21.8 \\
\hline $\mathrm{H}$ & 44.8 & 19.2 & 36.0 & $|5| \pm \mid .3$ & $0.387 \pm 0.004$ & -23.3 \\
\hline I & 35.0 & 15.0 & 50.0 & $116 \pm 1.6$ & $0.177 \pm 0.007$ & -34.4 \\
\hline J & 64.0 & 16.0 & 20.0 & $169 \pm 1.8$ & $0.335 \pm 0.005$ & -33.0 \\
\hline
\end{tabular}

Note: $n=3$.

Abbreviation: SD, standard deviation.

sizes that were less than $200 \mathrm{~nm}$ were selected. As shown in Table 1, formulations A, B, and E produced the smallest and most uniform droplet sizes compared to other selfnanoemulsifying formulations with the same oil concentration of $20 \%$. Formulation I also had small droplets (116 \pm 1.6 $\mathrm{nm}$ ) and a size distribution of $0.117 \pm 0.007$ in the presence of high oil concentrations (50\%). Overall, formulation I would be the best formula to use in a self-nanoemulsifying formulation.

Overall, the ternary phase diagrams demonstrate that, when there is an increase in the oil content in the formulations, the size of the droplets and the speed of self-emulsification also increased. However, the presence of a large amount of oil meant that the formulation quickly separated, indicating that this would not be stable after self-emulsification. This can be explained by the decrease in the amount of surfactants available for adsorption and a film that formed at the oil-water interface. Similar results were reported by Zhao et $\mathrm{al}^{43}$ who investigated a self-nanoemulsifying drug delivery system using zedoary essential oil in an oral delivery system. Zhao et $\mathrm{al}^{43}$ found that the size of the droplets gradually decreased from $180 \mathrm{~nm}$ until they reached $38 \mathrm{~nm}$ in size when the surfactant content rose from $30 \%$ to $75 \%$. They suggested that the decrease in droplet size was due to the existence of more surfactant at the oil-water interface that increased the stability of emulsions with nano-size droplets.

Zeta potential is the potential between the surface of a droplet and the dispersing liquid. It will vary based on the distance between the droplet surface and the ion. The zeta potential for optimum formulations was measured using a Malvern Zetasizer. In general, emulsions with positive or negative potentials of more than $30 \mathrm{mV}$ were considered to be stable. ${ }^{42}$ The zeta potential for the formulations in this study ranged between -21.8 and -34.4 . Formulation I had the best zeta potential (-34.4), indicating that it was more stable than any of the other formulations.

\section{Swietenia oil and surfactants mixtures' behavior on appearance and emulsification time of self-nanoemulsifying formulations}

A visual examination of the self-nanoemulsifying formulations revealed that they were transparent and yellowish in color. When the oil content was increased, the formulations became more yellow and the time of emulsification was reduced. Zhao et $\mathrm{al}^{43}$ found that emulsification time is affected by the increase in the surfactant concentration. These authors stated that, when there is an increase from $30 \%$ to $75 \%$ of the surfactant concentration, the time of emulsification rose from 1 to 5 minutes. Similar conclusions were also reported by Gao et a ${ }^{44}$ who confirmed that emulsification times will increase as the surfactant concentration increases.

System 1 showed a moderate time of emulsification, at around 25-130 seconds, then the time of emulsification was around 20-110 seconds for Systems 2 and 3, and, lastly, emulsification time was around $25-125$ seconds for Systems 4 and 5. Table 2 presents the results of a visual examination of the Swietenia oil self-nanoemulsifying formulations from System 1. Table 2 reveals that all formulations possessed different emulsification times with good spreading properties. Formulations A, B, E, G, and J took 42-58 \pm 0.5 seconds to emulsify, while $\mathrm{C}, \mathrm{F}$, and $\mathrm{H}$ self-nanoemulsifying formulations showed moderate emulsification times (29-37 \pm 0.5 seconds). Formulations D and I had the fastest emulsification times, at 27 and $28 \pm 0.5$ seconds, respectively. 
Table 2 Visual characteristics of Swietenia oil self-nanoemulsifying formulations

\begin{tabular}{llll}
\hline Formulation & Spreadability & $\begin{array}{l}\text { Time (s) } \\
\pm \mathbf{0 . 5}\end{array}$ & Appearance \\
\hline A & Spreadable & 45 & Transparent emulsion \\
B & Spreadable & 42 & Transparent emulsion \\
C & Spreadable & 35 & Transparent emulsion \\
D & Spreadable & 27 & $\begin{array}{l}\text { Transparent } \\
\text { (yellowish) emulsion }\end{array}$ \\
& Spreadable & 48 & Transparent emulsion \\
F & Spreadable & 29 & Transparent emulsion \\
G & Spreadable & 57 & Transparent emulsion \\
H & Spreadable & 37 & Transparent emulsion \\
I & Spreadable & 28 & Transparent \\
& & & (yellowish) emulsion \\
J & Spreadable & 58 & Transparent emulsion \\
\hline
\end{tabular}

Note: $n=3$.

The ratio of oil to surfactants will influence the self-emulsifying properties, which are required to produce formulations with nano-size droplets. Conversely, emulsification times are adversely affected by surfactant concentrations. These findings are in agreement with earlier studies that showed similar relationships between the emulsification times and the various concentrations of oil and surfactant mixtures. For example, Buyukozturk et $\mathrm{al}^{45}$ revealed a strong relationship between the mean droplet size of emulsions which contained surfactants with high levels of HLB and the changes in the oil-to-surfactant ratio. Bachynsky et $\mathrm{al}^{46}$ found that the self-emulsification properties are affected even with low amounts of oil in the system. Craig et $\mathrm{al}^{47}$ reported that formulations with good self-emulsification properties were significantly influenced by the concentration of oil, mentioning that formulations with good self-emulsification properties also have the ability to form clouds within 60 seconds with good spreading characteristics.
On the other hand, when the ratio of surfactants increases, the self-emulsifying process becomes difficult. The viscosity of the formulation would be increased with the increase in surfactant content, thus leading to a longer emulsification time. Emulsification times depend on the chemical structure of an oil and the proportions of oil, surfactants, and cosurfactants in the mixture. This study revealed that emulsification time was reversely affected by the concentrations of surfactants and cosurfactants in a mixture. When the amount of oil in a formulation was increased from $20 \%$ to $50 \%$, it meant that the concentration of surfactants and cosurfactants were decreased and emulsification times also increased (from 27 to 58 seconds). Overall, the emulsification time for each formulation was good, as each one formed a cloud in less than 60 seconds.

\section{Self-nanoemulsifying formulations' viscosity}

The viscosities of self-nanoemulsifying formulations that consisted of oil and surfactants are reported in Table 3. At ambient temperature, self-nanoemulsifying formulations were viscous. The viscosity ranged from as low as $102 \pm 3.9 \mathrm{cP}$ to as high as $143 \pm 2.7 \mathrm{cP}$. Formulation A was the most viscous formulation, with a viscosity of $143.1 \pm 2.7 \mathrm{cP}$, followed by formulation $\mathrm{B}$, with a viscosity of $139.7 \pm 3.2 \mathrm{cP}$. Formulation D had the lowest viscosity $(102.1 \pm 3.9 \mathrm{cP})$.

Table 3 illustrates that different self-nanoemulsifying formulations have different viscosity values. The viscosity properties and flow of self-nanoemulsifying formulations were affected by the different concentrations of oil and surfactants used. This phenomenon is demonstrated by the decrease in oil concentration and the increase in the concentrations of surfactants, showing that a high concentration of oil resulted in

Table 3 Viscosity values of Swietenia oil self-nanoemulsifying formulations

\begin{tabular}{|c|c|c|c|c|}
\hline Formulation & Labrafil ${ }^{\circledR} /$ Tween 20 (\%) & Capmul $^{\circledast / L a b r a s o l}{ }^{\circledR}$ (\%) & Swietenia oil (\%) & Viscosity $(c P) \pm S D$ \\
\hline $\bar{A}$ & 32.0 & 48.0 & 20.0 & $143.1 \pm 2.7$ \\
\hline B & 40.0 & 40.0 & 20.0 & $139.7 \pm 3.2$ \\
\hline C & 32.0 & 32.0 & 36.0 & $120.7 \pm 4.5$ \\
\hline D & 40.0 & 10.0 & 50.0 & $102.1 \pm 3.9$ \\
\hline $\mathrm{E}$ & 48.0 & 32.0 & 20.0 & $135.7 \pm 3.1$ \\
\hline $\mathrm{F}$ & 38.4 & 25.6 & 36.0 & $112.3 \pm 3.5$ \\
\hline G & 56.0 & 24.0 & 20.0 & $132.9 \pm 2.6$ \\
\hline $\mathrm{H}$ & 44.8 & 19.2 & 36.0 & $111.3 \pm 3.8$ \\
\hline I & 35.0 & 15.0 & 50.0 & $109.1 \pm 4.1$ \\
\hline J & 64.0 & 16.0 & 20.0 & $130.4 \pm 3.2$ \\
\hline
\end{tabular}

Note: $n=3$.

Abbreviations: $\mathrm{CP}$, centipoises; $\mathrm{SD}$, standard deviation. 


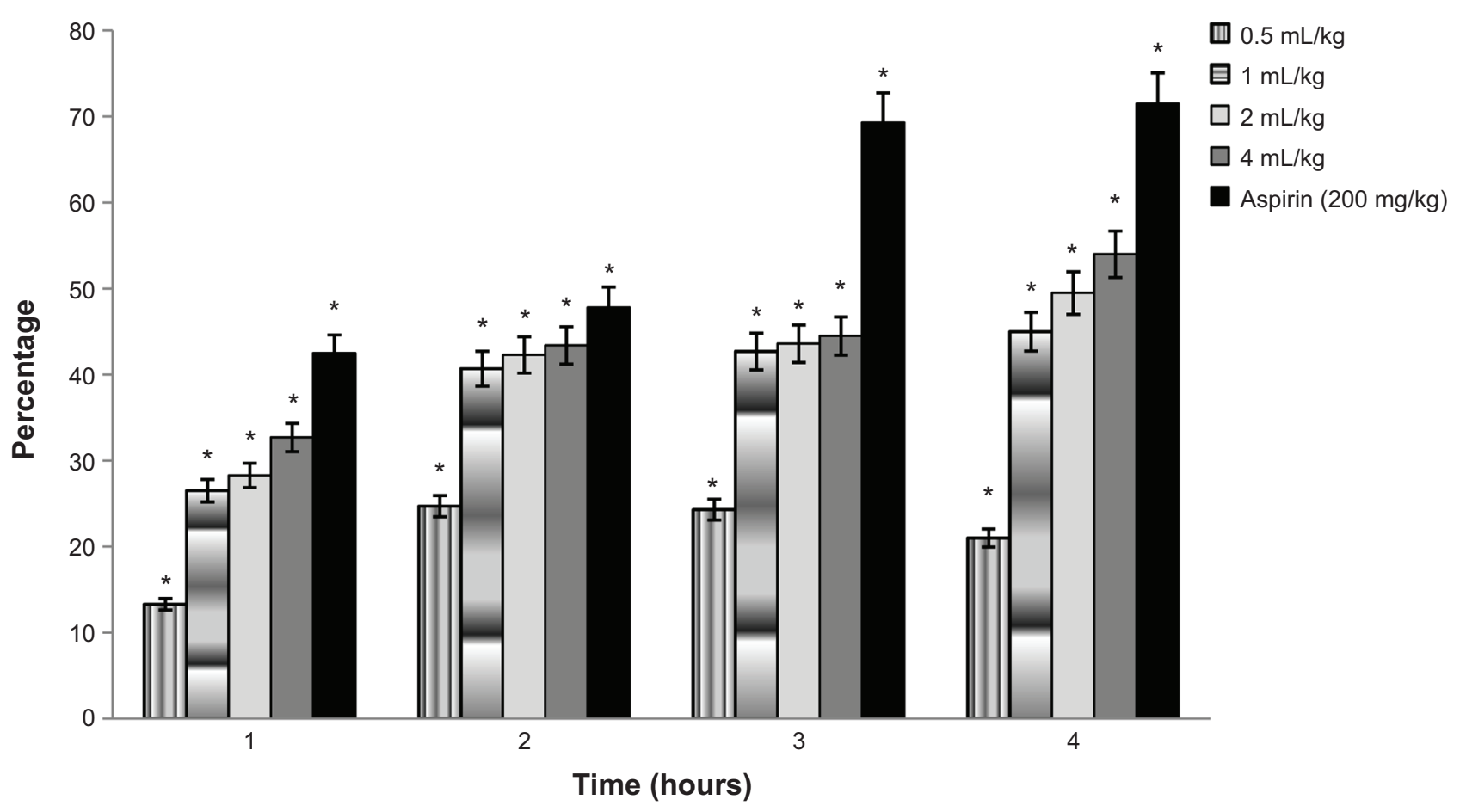

Figure 6 Percentage of anti-inflammatory inhibition of Swietenia oil used at different concentrations. Note: *Indicates significance when $P<0.05$.

low viscosity values. Increased viscosity could require greater shear forces for dispersion and mean that the formulation would take a longer time to emulsify. In this study, all the formulations achieved self-emulsification with gentle agitation. In addition, the time of emulsification was influenced by the ratio of oil to surfactants. Self-emulsifying formulations having low viscosity required a short time of emulsification compared to those formulations with higher viscosity.

\section{Anti-inflammatory activity of Swietenia oil self-nanoemulsifying systems}

The present study investigated the anti-inflammatory activity of Swietenia oil. The anti-inflammatory properties of Swietenia oil solutions, formulations of different concentrations $(0.5,1,2$, and $4 \mathrm{~mL} / \mathrm{kg})$, aspirin $(200 \mathrm{mg} / \mathrm{kg})$ (used as a positive control), and negative control were compared using carrageenan injected into the paws of 60 rats to induce edema. The effect of Swietenia oil solution on carrageenan-induced paw edema in rats is shown in Figure 6, where a significant difference in the percentages of anti-inflammatory activity can be observed after 1, 2, 3, and 4 hours $(P<0.05)$.

The highest level of anti-inflammatory action was seen in rats treated with $4 \mathrm{~mL} / \mathrm{kg}$ of Swietenia oil (54\%). As shown in Table 4, these results were better than those of any other formulation except for aspirin, which had a 71.5\% inhibition effect, making it significantly more effective than the $4 \mathrm{~mL} / \mathrm{kg}$ of Swietenia oil.

Table 4 Changes in rat hind paw volume and the percentage of inhibition of Swietenia oil solutions at different oil concentrations

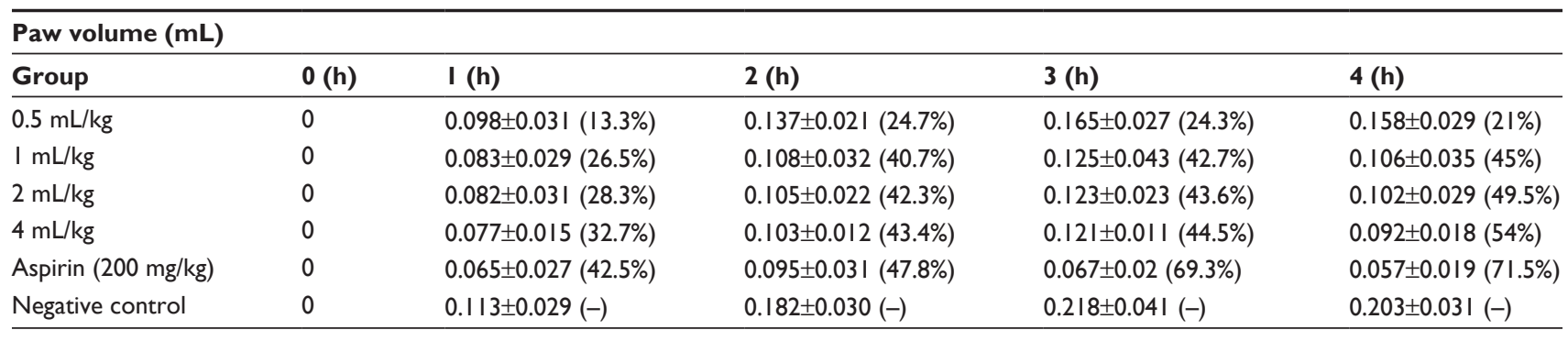

Notes: Values are mean \pm standard deviation. $n=6$ animals in each group. Abbreviation: h, hours. 


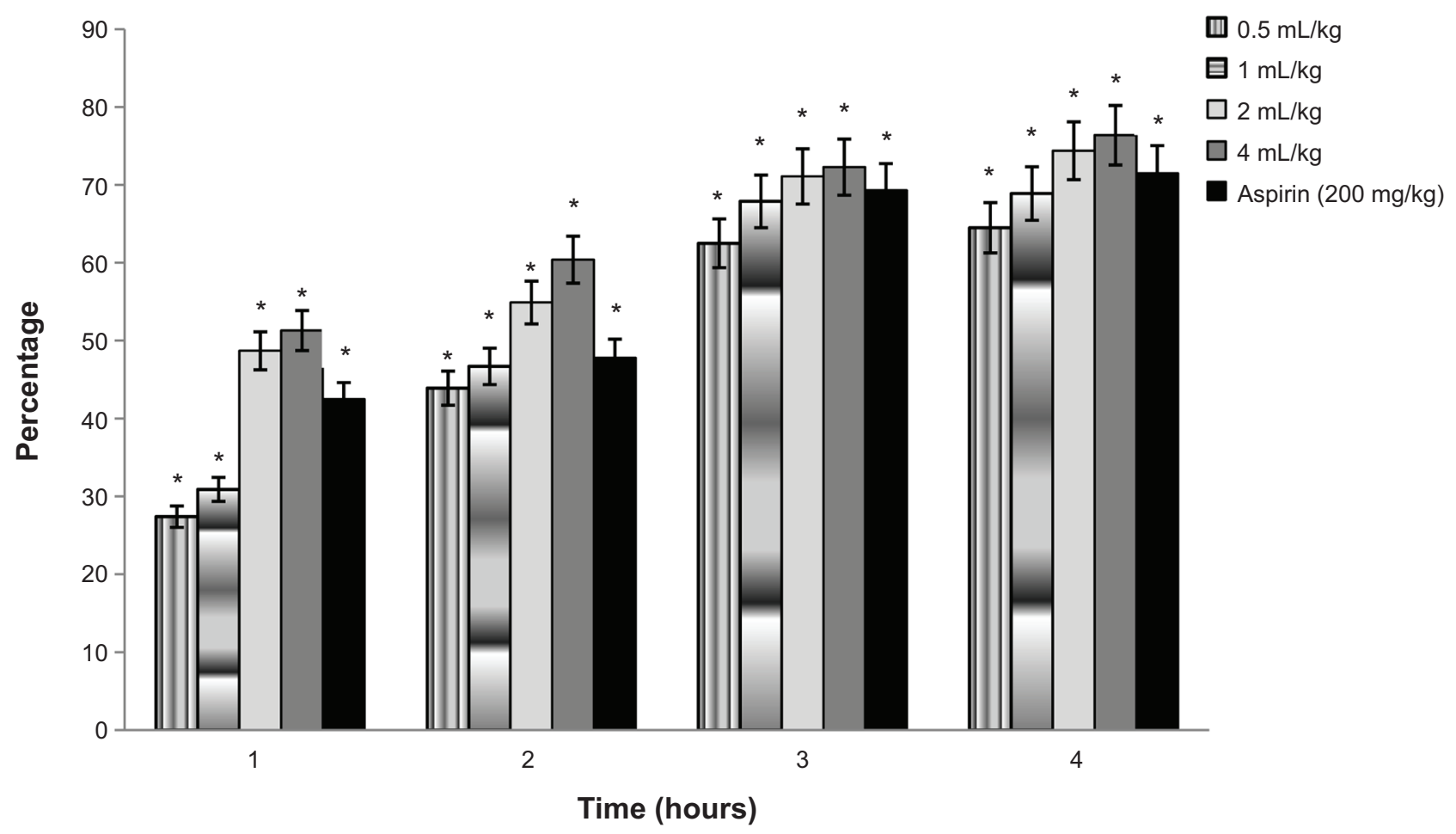

Figure 7 Percentage of anti-inflammatory inhibition of Swietenia oil at different concentrations in self-emulsifying formulations.

Note: *Indicates significance when $P<0.05$.

The anti-inflammatory effectiveness of Swietenia oil at different concentrations $(0.5,1,2$, and $4 \mathrm{~mL} / \mathrm{kg})$ in the form of a self-nanoemulsifying formulation over a period of 4 hours was almost as high as that of aspirin (Figure 7). The highest level of anti-inflammatory activity was observed with dosages of $4 \mathrm{~mL} / \mathrm{kg}$ with a mean inhibition of $76.4 \%$. This was followed by a $2 \mathrm{~mL} / \mathrm{kg}$ dose (74.5\%). These findings are significantly higher than the anti-inflammatory effect of a $200 \mathrm{mg} / \mathrm{kg}$ dosage of aspirin. The inhibition activity of Swietenia oil self-nanoemulsifying formulations $(0.5 \mathrm{~mL} / \mathrm{kg}$ and $1 \mathrm{~mL} / \mathrm{kg}$ ) was $64.5 \%$ and $68.9 \%$, respectively, as shown in Table 5.

The results depicted in Table 5 demonstrate that there are significant differences in the anti-inflammatory properties of different Swietenia oil preparations compared to the same concentrations of oil in the form of solution and in self-nanoemulsifying formulations. The effect was higher in self-nanoemulsifying systems, and this may be explained by the presence of smaller droplets that would increase the absorption of Swietenia oil.

\section{Conclusion}

Swietenia oil self-nanoemulsifying formulations were prepared successfully by blending the oil with different types of surfactants. The self-nanoemulsifying systems were sensitive to the oil/surfactants ratios and the properties of the surfactants phase. The self-nanoemulsifying formulations were significantly improved and had better self-nanoemulsifying

Table 5 Changes in rat hind paw volume and the percentage of inhibition of self-emulsifying formulations of Swietenia oil at different oil concentrations

\begin{tabular}{llllll}
\hline Paw volume (mL) & & & & \\
\hline Group & $\mathbf{O}(\mathbf{h})$ & $\mathbf{I}(\mathbf{h})$ & $\mathbf{2}(\mathbf{h})$ & $\mathbf{3}(\mathbf{h})$ & $\mathbf{4}(\mathbf{h})$ \\
\hline $0.5 \mathrm{~mL} / \mathrm{kg}$ & 0 & $0.082 \pm 0.029(27.4 \%)$ & $0.102 \pm 0.025(43.9 \%)$ & $0.08 \pm 0.015(62.5 \%)$ & $0.072 \pm 0.072(64.5 \%)$ \\
$\mathrm{I} \mathrm{mL} / \mathrm{kg}$ & 0 & $0.078 \pm 0.010(30.9 \%)$ & $0.097 \pm 0.020(46.7 \%)$ & $0.07 \pm 0.017(67.9 \%)$ & $0.063 \pm 0.018(68.9 \%)$ \\
$2 \mathrm{~mL} / \mathrm{kg}$ & 0 & $0.058 \pm 0.018(48.7 \%)$ & $0.082 \pm 0.035(54.9 \%)$ & $0.063 \pm 0.019(71.1 \%)$ & $0.052 \pm 0.012(74.4 \%)$ \\
$4 \mathrm{~mL} / \mathrm{kg}$ & 0 & $0.055 \pm 0.016(51.3 \%)$ & $0.07 \pm 0.02(60.4 \%)$ & $0.06 \pm 0.017(72.3 \%)$ & $0.048 \pm 0.018(76.4 \%)$ \\
Aspirin $(200 \mathrm{mg} / \mathrm{kg})$ & 0 & $0.065 \pm 0.027(42.5 \%)$ & $0.095 \pm 0.031(47.8 \%)$ & $0.067 \pm 0.020(69.3 \%)$ & $0.057 \pm 0.018(71.5 \%)$ \\
Negative control & 0 & $0.113 \pm 0.029(-)$ & $0.182 \pm 0.030(-)$ & $0.218 \pm 0.041(-)$ & $0.203 \pm 0.031(-)$ \\
\hline
\end{tabular}

Notes: Values are mean \pm standard deviation. $n=6$ animals in each group. Abbreviation: $h$, hours. 
properties when Tween 20 was added to the surfactants mixture. Adding Tween 20 as a hydrophilic surfactant (20\%-50\%) to the formulations reduced the size of the oil droplets. Emulsification times increased when more hydrophilic surfactant was added to the formulation because of the high viscosity of the hydrophilic surfactant. Emulsification times were faster when there was an increase in the formulation's oil content, but this led to poor self-nanoemulsifying systems with larger oil droplets, and the mixture separated after a few minutes. The Swietenia oil solution had less antiinflammatory activity when compared to the positive control, but the anti-inflammatory activity of Swietenia oil improved when the oil was applied in the form of self-nanoemulsifying systems, as it exhibited higher anti-inflammatory activity compared to the positive controls.

\section{Disclosure}

The authors report no conflicts of interest in this work.

\section{References}

1. Forgiarini A, Esquena J, González C, Solans C. Formation of nanoemulsions by low-energy emulsification methods at constant temperature. Langmuir. 2001;17(7):2076-2083.

2. Porras M, Solans C, González C, Gutiérreza JM. Properties of water-in-oil (W/O) nano-emulsions prepared by a low-energy emulsification method. Colloids Surf A Physicochem Eng Asp. 2008; 324(1-3):181-188.

3. Saberi AH, Fang Y, McClements DJ. Fabrication of vitamin E-enriched nanoemulsions: factors affecting particle size using spontaneous emulsification. J Colloid Interface Sci. 2013;391:95-102.

4. Fernandez $\mathrm{P}$, André V, Rieger J, Kühnle A. Nano-emulsion formation by emulsion phase inversion. Colloids Surf A Physicochem Eng Asp. 2004; 251(1):53-58.

5. Ee SL, Duan X, Liew J, Nguyen QD. Droplet size and stability of nano-emulsions produced by the temperature phase inversion method. Chem Eng J. 2008;140(1-3):626-631.

6. Salvia-Trujillo L, Rojas-Graü MA, Soliva-Fortuny R, Martín-Belloso O. Effect of processing parameters on physicochemical characteristics of microfluidized lemongrass essential oil-alginate nanoemulsions. Food Hydrocoll. 2013;30(1):401-407.

7. Shah P, Bhalodia D, Shelat P. Nanoemulsion: a pharmaceutical review. Systematic Reviews in Pharmacy. 2010;1(1):24-32.

8. Chouksey R, Pandey H, Jain AK, Soni H, Saraogi GK. Preparation and evaluation of the self emulsifying drug delivery system containing atorvastatin HMG-CoA inhibiter. Int J Pharm Pharm Sci. 2011; 3(3):147-152.

9. Seo YG, Kim DH, Ramasamy T, et al. Development of docetaxel-loaded solid self-nanoemulsifying drug delivery system (SNEDDS) for enhanced chemotherapeutic effect. Int J Pharm. 2013;452(1-2):412-420.

10. Pal VK. Self emulsifying drug delivery system. Journal of Pharmaceutical Research and Opinion. 2011;1(3):80-84.

11. Zhang L, Zhu W, Yang C, et al. A novel folate-modified selfmicroemulsifying drug delivery system of curcumin for colon targeting. Int J Nanomedicine. 2012;7:151-162.

12. Yang S, Gursoy RN, Lambert G, Benita S. Enhanced oral absorption of paclitaxel in a novel self-microemulsifying drug delivery system with or without concomitant use of P-glycoprotein inhibitors. Pharm Res. 2004;21(2):261-270.
13. Porter CJ, Trevaskis NL, Charman WN. Lipids and lipid-based formulations: optimizing the oral delivery of lipophilic drugs. Nat Rev Drug Discov. 2007;6(3):231-248

14. Pouton CW, Porter CJ. Formulation of lipid-based delivery systems for oral administration: materials, methods and strategies. Adv Drug Deliv Rev. 2008;60(6):625-637.

15. Harshal DM, Tanvir S, Dheeraj B, Rajendra DW. Design and development of solid self-micro-emulsifying drug delivery system (SMEDDS) of fenofibrate. Int J Pharm Pharm Sci. 2011;3:163-166.

16. Sharma S, Sharma AD, Naseer MA, Singh R. Formulation and evaluation of self emulsifying drug delivery system of ibuprofen using castor oil. Int J Pharm Pharm Sci. 2011;3:299-302.

17. Liu W, Tian R, Hu W, et al. Preparation and evaluation of selfmicroemulsifying drug delivery system of baicalein. Fitoterapia. 2012;83(8):1532-1539.

18. López-Montilla JC, Herrera-Morales PE, Pandey S, Shah DO. Spontaneous emulsification: mechanisms, physicochemical aspects, modeling, and applications. J Dispers Sci Technol. 2002;23(1-3):219-268.

19. Ostertag F, Weiss J, McClements DJ. Low-energy formation of edible nanoemulsions: factors influencing droplet size produced by emulsion phase inversion. J Colloid Interface Sci. 2012;388(1):95-102.

20. Gursoy RN, Benita S. Self-emulsifying drug delivery systems (SEDDS) for improved oral delivery of lipophilic drugs. Biomed Pharmacother. 2004;58(3):173-182.

21. Rao J, McClements DJ. Food-grade microemulsions, nanoemulsions and emulsions: fabrication from sucrose monopalmitate and lemon oil. Food Hydrocoll. 2011;25(6):1413-1423.

22. André T, Lemes MR, Grogan J, Gribel R. Post-logging loss of genetic diversity in a mahogany (Swietenia macrophylla King, Meliaceae) population in Brazilian Amazonia. For Ecol Manage. 2008;255(2):340-345.

23. Nair KSS. Pest Outbreaks in Tropical Forest Plantations: Is There a Greater Risk for Exotic Tree Species? Jakarta, Indonesia: Center for International Forestry Research; 2001.

24. Goh BH, Kadir HA. In vitro cytotoxic potential of Swietenia macrophylla King seeds against human carcinoma cell lines. Journal of Medicinal Plants Research. 2011;5(8):1395-1404.

25. Bacsal K, Chavez L, Diaz I, et al. The effect of Swietenia mahagoni (Mahogany) seed extract on indomethacin-induced gastric ulcers in female Sprague-Dawley rats. Acta Med Philipp. 1997;3:127-139.

26. Wu SF, Lin CK, Chuang YS, et al. Anti-hepatitis C virus activity of 3-hydroxy caruilignan C from Swietenia macrophylla stems. $J$ Viral Hepat. 2012;19(5):364-370.

27. Alrdahe SS, Abdulla MA, Razak SA, Kadir FA, Hassandarvish P. Gastroprotective activity of Swietenia mahagoni seed extract on ethanolinduced gastric mucosal injury in rats. World Acad Sci Eng Technol. 2010;43:883-887.

28. Majid MA, Rahman IM, Shipar MA, Helal-Uddin M, Chowdhury R. Physico-chemical characterization, antimicrobial activity and toxicity analysis of Swietenia mahagoni seed oil. International Journal of Agriculture and Biology. 2004;6(2):350-354.

29. Das A, Jeba Sunilson JA, Gopinath R, Radhamani S, Nilugal K. Antinociceptive activity of the fruits of Swietenia macrophylla King. Journal of Pharmacy Research. 2009;2(9):1367-1369.

30. Maiti A, Dewanjee S, Mandal SC, Annadurai S. Exploration of antimicrobial potential of methanol and water extract of seeds of Swietenia macrophylla (family: Meliaceae), to substantiate folklore claim. Iranian Journal of Pharmacology and Therapeutics. 2007;6(1):99-102.

31. Maiti A, Dewanjee S, Mandal SC. In vivo evaluation of antidiarrhoeal activity of the seed of Swietenia macrophylla King (Meliaceae). Tropical Journal of Pharmaceutical Research. 2007;6(2):711-716.

32. Eid AMM, Elmarzugi NA, EL-Enshasy HA, Arafat OM. A novel Swietenia macrophylla oil self-nanoemulsifying system: development and evaluation. Int J Pharm Pharm Sci. 2013;5(3):639-644.

33. Winter CA, Risley EA, Nuss GW. Carrageenin-induced edema in hind paw of the rat as an assay for anti-inflammatory drugs. Exp Biol Med. 1962;111(3):544-547. 
34. Ahmed O, Salahuddin M, Rizwana I, Aleem M, Sharma P. Synthesis, characterization and biological evaluation of novel thiazolidinone derivatives as anti-inflammatory agents. Indo American Journal of Pharmaceutical Research. 2013;3(10):8121-8126.

35. Sharma S, Kumar A, Sahni JK, Ali J, Baboota S. Nanoemulsion based hydrogel containing omega 3 fatty acids as a surrogate of betamethasone dipropionate for topical delivery. Adv Sci Lett. 2012;6(1):221-231.

36. Gupta M, Mazumder UK, Kumar RS, et al. Anti-inflammatory, analgesic and antipyretic effects of methanol extract from Bauhinia racemosa stem bark in animal models. J Ethnopharmacol. 2005;98(3):267-273.

37. Moody JO, Robert VA, Connolly JD, Houghton PJ. Anti-inflammatory activities of the methanol extracts and an isolated furanoditerpene constituent of Sphenocentrum jollyanum Pierre (Menispermaceae). J Ethnopharmacol. 2006;104(1-2):87-91.

38. Richard SW, Marius L, Noya S, Innocent Pierre G, Germaine NO. Anti-inflammatory, analgesic and antipyretic effects of Lepidagathis anobrya Nees (Acanthaceae). Afr J Tradit Complement Altern Med. 2011;8(4):420-424.

39. Pouton CW. Lipid formulations for oral administration of drugs: nonemulsifying, self-emulsifying and 'self-microemulsifying'drug delivery systems. Eur J Pharma Sci. 2000;11(Supp1 2):S93-S98.

40. Gao P, Morozowich W. Development of supersaturable self emulsifying systems (SMEDDS) for oral bioavailability enhancement of simvastatinin drug delivery system formulations for improving the oral absorbing beagle dogs. Int J Pharm. 2004;274:65-73.
41. Mahdi ES, Sakeena MH, Abdulkarim MF, Abdullah GZ, Sattar MA, Noor AM. Effect of surfactant and surfactant blends on pseudoternary phase diagram behavior of newly synthesized palm kernel oil esters. Drug Des Devel Ther. 2011;5:311-323.

42. Stolnik S, Dunn SE, Garnett MC, et al. Surface modification of poly(lactideco-glycolide) nanospheres by biodegradable poly(lactide)-poly (ethylene glycol) copolymers. Pharm Res. 1994;11(12):1800-1808.

43. Zhao Y, Wang C, Chow AH, et al. Self-nanoemulsifying drug delivery system (SNEDDS) for oral delivery of Zedoary essential oil: formulation and bioavailability studies. Int J Pharm. 2010;383(1-2):170-177.

44. Gao ZG, Choi HG, Shin HJ, et al. Physicochemical characterization and evaluation of a microemulsion system for oral delivery of cyclosporin A. Int J Pharm. 1998;161(1):75-86.

45. Buyukozturk F, Benneyan JC, Carrier RL. Impact of emulsion-based drug delivery systems on intestinal permeability and drug release kinetics. Journal Control Release. 2010;142(1):22-30.

46. Bachynsky MO, Shah NH, Patel CI, Malick AW. Factors affecting the efficiency of a self-emulsifying oral delivery system. Drug Dev Ind Pharm. 1997;23(8):809-816.

47. Craig DQM, Barker SA, Banning D, Booth SW. An investigation into the mechanisms of self-emulsification using particle size analysis and low frequency dielectric spectroscopy. Int J Pharm. 1995;114(1):103-110.
International Journal of Nanomedicine

\section{Publish your work in this journal}

The International Journal of Nanomedicine is an international, peerreviewed journal focusing on the application of nanotechnology in diagnostics, therapeutics, and drug delivery systems throughout the biomedical field. This journal is indexed on PubMed Central, MedLine, CAS, SciSearch $®$, Current Contents $\AA /$ Clinical Medicine,

\section{Dovepress}

Journal Citation Reports/Science Edition, EMBase, Scopus and the Elsevier Bibliographic databases. The manuscript management system is completely online and includes a very quick and fair peer-review system, which is all easy to use. Visit http://www.dovepress.com/ testimonials.php to read real quotes from published authors. 